\title{
Gambaran maloklulsi pada siswa kelas 10 di SMA Negeri 9 Manado
}

\author{
${ }^{1}$ Gabrielly F. J. Rorong \\ ${ }^{2}$ Damajanty H. C. Pangemanan \\ ${ }^{3}$ Juliatri \\ ${ }^{1}$ Kandidat Skripsi Program Studi Kedokteran Gigi Fakultas Kedokteran \\ ${ }^{2}$ Bagian Fisiologi Fakultas Kedokteran \\ ${ }^{3}$ Program Studi Kedokteran Gigi Fakultas Kedokteran \\ Universitas Sam Ratulangi Manado \\ Email: brillyrorong026@gmail.com
}

\begin{abstract}
Malocclusion is an important oral health issue. Its effects on oral function and facial aesthetics have become a major concern. This study aimed to obtain the profile of malocclusion in grade 10 students of SMA Negeri 9 Manado. This was a descriptive study with a cross-sectional design. Population in this study was all students in grade 10 at SMA Negeri 9 Manado totaling 544 students. Samples were 30 students obtained by using purposive sampling technique. The results showed that the majority of respondents had malocclusion of Angle class I classification Dewey modification as many as $23.3 \%$ of type 2 and $20 \%$ of type 1. Malocclusion of Angle class I type 5 was found in $3.3 \%$ of respondents. Respondents with Angle Class II Division 1 and Division 2 were 13.3\% each. Respondents with Angle Class III type 1 were as many as $6.7 \%$. Conclusion: Malocclusion Angle classification Dewey modification with the highest percentage was class I type 2. Malocclusion of class II division 1 and division 2 had the same percentage. Of malocclusion class III, only the type 1 was found.
\end{abstract}

Keywords: malocclusion, senior high school students

\begin{abstract}
Abstrak: Maloklusi merupakan salah satu masalah kesehatan gigi dan mulut yang cukup besar. Pengaruhnya terhadap fungsi mulut dan estetika wajah telah menjadi perhatian besar di bidang kesehatan. Penelitian ini bertujuan untuk mengetahui gambaran maloklusi pada siswa kelas 10 di SMAN 9 Manado. Penelitian ini menggunakan metode deskriptif dengan desain penelitian potong lintang. Populasi penelitian ini ialah seluruh siswa kelas 10 di SMA Negeri 9 Manado yang berjumlah 544 orang. Jumlah sampel sebanyak 30 orang yang diperoleh dengan teknik purposive sampling. Hasil penelitian menunjukkan jenis maloklusi terbanyak dengan klasifikasi Angle kelas I modifikasi Dewey tipe 2 sebanyak 23,3\% dan tipe 1 sebanyak 20\% responden. Jenis maloklusi Angle kelas I tipe 5 paling sedikit yaitu sebanyak 3,3\%. Responden dengan Angle kelas II divisi 1 dan divisi 2 masing-masing sebanyak 13,3\%. Responden dengan Angle kelas III tipe 1 sebanyak 6,7\%. Simpulan: Maloklusi klasifikasi Angle modifikasi Dewey yang terbanyak ialah kelas I tipe 2. Maloklusi kelas II divisi 1 dan divisi 2 sama banyak. Maloklusi kelas III yang ditemukan hanya tipe 1 .
\end{abstract}

Kata kunci: maloklusi, siswa SMA

Penampilan fisik termasuk gigi merupakan aspek yang sangat penting untuk menumbuhkan kepercayaan diri seseorang. Gigi dengan susunan yang rapi dan senyum yang menawan akan memberikan efek yang positif pada tiap tingkat sosial, sedangkan gigi yang tidak teratur dan protrusi akan memberikan efek negatif. Banyak masyarakat melakukan perawatan ortodonti untuk memperbaiki penampilan, dan tentu saja keinginan yang terbesar biasanya berhubungan dengan estetika untuk 
meningkatkan kepercayaan diri. ${ }^{1}$

Maloklusi adalah masalah oklusi gigi hasil dari adaptasi orofasial berbagai faktor etiologi, yang mengakibatkan berbagai implikasi mulai dari ketidakpuasan estetika pada perubahan berbicara, mengunyah, menelan, gangguan sendi temporomandibular dan rasa sakit orofasial. $^{2}$ Maloklusi merupakan kelainan hubungan antara rahang atas dan rahang bawah ketika rahang menutup. Istilah ini diciptakan oleh Edward Angle, "bapak ortodontik modern”, sebagai turunan dari oklusi, yang mengacu pada cara gigi lawan bertemu (mal + oklusi = kesalahan oklusi). Maloklusi dapat terjadi karena beberapa penyebab seperti faktor genetik dan lingkungan, tetapi kebiasaan oral pada anak-anak juga berpengaruh terhadap pengembangan oklusi. ${ }^{3}$

Maloklusi merupakan salah satu masalah kesehatan gigi dan mulut yang cukup besar, hal ini ditambah dengan tingkat kesadaran perawatan gigi yang masih rendah dan kebiasaan buruk seperti mengisap ibu jari atau benda-benda lain, karena jumlah dan keparahan maloklusi akan terus meningkat maka maloklusi seharusnya dicegah ataupun ditangani. ${ }^{4}$

Masalah maloklusi dan pengaruhnya terhadap fungsi mulut dan estetika wajah telah menjadi perhatian besar di bidang kesehatan. ${ }^{5}$ Berdasarkan data World Health Organization (WHO) maloklusi merupakan masalah kesehatan gigi dan mulut dengan peringkat ketiga, peringkat kedua penyakit periodontal dan peringkat pertama karies gigi. $^{6}$ Penelitian Silva et al tentang maloklusi tahun 2001 di Amerika Latin pada anak usia 12-18 tahun menunjukkan bahwa lebih dari 93\% anak menderita maloklusi. ${ }^{7}$ Penelitian yang dilakukan oleh Alatrach pada tahun 2014 menyebutkan bahwa lebih dari $60 \%$ anak-anak di Siria menderita maloklusi. ${ }^{6}$ Demikian juga penelitian yang dilakukan oleh Lagana et al tahun 2013 pada anak-anak sekolah berumur 7 - 15 tahun di Tirana menyatakan bahwa dari total 2.707 sampel, 40,4\% menderita maloklusi kelas I, 29.2\% menderita maloklusi kelas II, dan 3,2\% menderita maloklusi kelas III. ${ }^{8}$
Berdasarkan laporan hasil Riset Kesehatan Dasar (Riskesdas) Nasional tahun 2013, sebanyak 14 provinsi mengalami masalah gigi dan mulut yaitu 25,9\% dan juga prevalensi maloklusi di Indonesia masih sangat tinggi sekitar $80 \%$ dari jumlah penduduk. Berdasarkan hasil penelitian Oktavia tentang maloklusi pada remaja SMU di kota Medan tahun 2007 dengan menggunakan skor HMAR menunjukkan bahwa prevalensi maloklusi sebesar 60,5\% dengan kebutuhan perawatan ortodonti sebesar 23\%., Penelitian yang dilakukan oleh Rosani pada pasien ortodontik Rumah Sakit Gigi dan Mulut Fakultas Kedokteran Gigi Universitas Hasanudin (RSGM UNHAS) menunjukkan $40 \%$ yang mengalami maloklusi. Penelitian dilakukan pada siswa Sekolah Menengah Pertama (SMP) di kecamatan Malalayang oleh Astuti tahun 2011 yang mengalami maloklusi yaitu $60,2 \%$ dan yang mengalami oklusi normal $2,2 \%{ }^{4}$

Penelitian disekolah khususnya SMA, belum pernah dilakukan. Berdasarkan latar belakang masalah di atas, maka peneliti tertarik untuk melakukan penelitian mengenai maloklusi pada siswa kelas 10 Sekolah Menengah Atas Negeri 9 Manado.

\section{METODE PENELITIAN}

Penelitian ini bersifat deskriptif dengan desain penelitian potong lintang. Penelitian ini dilakukan di sekolah Menengah Atas (SMA) Negeri 9 Manado yang dilaksanakan pada bulan September 2015. Populasi penelitian ini ialah seluruh siswa kelas 10 di SMA Negeri 9 Manado yang berjumlah 544 siswa. Teknik pengambilan sampel yang digunakan ialah purposive sampling.

\section{HASIL PENELITIAN}

Sampel penelitian ini yaitu siswa kelas 10 sebanyak 30 orang. Tabel 1 menunjukkan bahwa responden terbanyak ialah responden jenis kelamin perempuan yaitu sebanyak 22 orang dan sisanya ialah responden laki-laki yaitu sebanyak 8 orang. Pada jenis maloklusi kelas 1 , responden 
perempuan sebanyak 16 orang sedangkan responden laki-laki sebanyak 4 orang. Pada jenis maloklusi kelas 2, responden perempuan sebanyak 5 orang sedangkan responden laki-laki sebanyak 3 orang. Dan untuk jenis maloklusi kelas 3, responden perempuan dan laki-laki masing-masing sebanyak 1 orang.

Tabel 1. Karakteristik Responden menurut Jenis Kelamin dan Kelas Maloklusi.

\begin{tabular}{lcccc}
\hline \multirow{2}{*}{ Jenis } & \multicolumn{3}{c}{ Kelas Maloklusi } & Total \\
\cline { 2 - 4 } Kelamin & Kelas & Kelas & Kelas & \\
& 1 & 2 & 3 & \\
\hline Laki-Laki & 4 & 3 & 1 & 8 \\
Perempuan & 16 & 5 & 1 & 22 \\
Total & 20 & 8 & 2 & 30 \\
\hline
\end{tabular}

Tabel 2 menunjukkan responden dengan gigi insisivus atas protusif sebanyak 7 orang, diikuti dengan responden dengan gigi berjejal di anterior sebanyak 6 orang dan responden dengan gigitan silang posterior sebanyak 4 orang. Sedangkan responden dengan gigitan silang di anterior sebanyak 2 orang dan responden dengan gigi molar ke arah mesial sebanyak 1 orang.

Tabel 2. Distribusi Karakteristik Responden Menurut Maloklusi Kelas I Angle Modifikasi Dewey (Neutrocclusion).

\begin{tabular}{lcc}
\hline \multicolumn{1}{c}{ Tipe } & $\mathrm{n}$ & $\%$ \\
\hline Tipe 1. Gigi berjejal di anterior & 6 & 20,0 \\
Tipe 2. Gigi insisivus atas protusif & 7 & 23,3 \\
Tipe 3. Gigitan silang anterior & & \\
Tipe 4. Gigitan silang posterior & 2 & 6,7 \\
Tipe 5. Gigi molar permanen ke & 4 & 13,3 \\
arah mesial karena ektraksi gigi & 1 & 3,3 \\
$\begin{array}{l}\text { premolar kedua atau molar kedua } \\
\text { sulung }\end{array}$ & & \\
$\quad$ & 20 & 66,7 \\
\hline
\end{tabular}

Tabel 3 menunjukkan responden dengan gigi insisivus atas protusif dan gigi insisivus sentralis atas retroklinasi masingmasing sebanyak 4 orang.

Tabel 4 menunjukkan responden dengan gigi insisivus anterior edge to edge sebanyak 2 orang.
Tabel 3. Distribusi Karakteristik Responden Menurut Maloklusi Kelas II Angel Modifikasi Dewey (Distocclusion).

\begin{tabular}{llc}
\hline \multicolumn{1}{c}{ Tipe } & $\mathrm{n}$ & $\%$ \\
\hline $\begin{array}{l}\text { Divisi 1. Gigi insisivus } \\
\text { atas protusi }\end{array}$ & 4 & 13,3 \\
$\begin{array}{l}\text { Divisi 2. Gigi insisivus } \\
\text { sentralis atas retroklinas } \\
\quad \text { Total }\end{array}$ & 4 & 13,3 \\
$\quad$ & 8 & 26,6 \\
\hline
\end{tabular}

Tabel 4. Distribusi Karakteristik Responden Menurut Maloklusi Kelas III Angel Modifikasi Dewey (Mesioocclusion).

\begin{tabular}{ccc}
\hline Tipe & $\mathrm{N}$ & $\%$ \\
\hline $\begin{array}{c}\text { Tipe 1. Hubungan gigi } \\
\text { insisivus anterior edge }\end{array}$ & 2 & 6,7 \\
to edge & & 0 \\
$\begin{array}{c}\text { Tipe 2. Gigi insisivus } \\
\text { bawah berjejal }\end{array}$ & 0 & 0 \\
$\begin{array}{c}\text { Tipe 3. Gigi geligi insisivus } \\
\text { atas berjejal } \\
\text { Total }\end{array}$ & 0 & \\
\hline
\end{tabular}

\section{BAHASAN}

Hasil penelitian menunjukkan bahwa responden dengan jenis kelamin perempuan yaitu sebanyak 22 orang dan sisanya adalah responden laki-laki yaitu sebanyak 8 orang.

Pada penelitian ini subjek dengan maloklusi kelas I memiliki jumlah yang paling banyak dari keseluruhan populasi. Pada penelitian ini didapatkan total jumlah maloklusi Angle kelas I 66,7\% responden, maloklusi Angle kelas II 26,7\% sedangkan maloklusi Angle kelas III 6,7\% responden. Hasil penelitian ini serupa dengan hasil penelitian Wijayanti dkk pada anak usia 911 tahun di daerah Cempaka Putih kota Jakarta pada tahun 2014 yang menunjukkan hasil sebanyak $65,3 \%$ dari populasi siswa diketahui memiliki maloklusi kelas I, maloklusi kelas II 31,6\% dan maloklusi kelas III 3,1\%. Penelitian ini juga serupa dengan hasil penelitian Mridula T dkk pada anak remaja di kota Jaipur India tahun 2009 yang menunjukkan hasil maloklusi klasifikasi Angle modifikasi Dewey paling banyak kelas I yaitu 57,9\% kelas II 7,4\% dan kelas III 1,4 \% responden, hasil penelitian Sharma $\mathrm{J}$ menunjukkan hasil 
yang serupa yaitu pada kelas I yaitu $62,28 \%$ responden, kelas II 29,4\% responden dan kelas III 8,2\% responden. Hasil ini sesuai dengan banyak penelitian tentang maloklusi, salah satunya di Iraq sebanyak 73,88\% anak usia 14 tahun mengalami maloklusi klasifikasi Angle Kelas I. ${ }^{10-13}$

Angle menyatakan maloklusi Angle kelas I sering terjadi dan mempunyai hubungan dentofacial yang normal. Hubungan ini terjadi pada orang yang relative mempunyai profil wajah yang lurus. Pada populasi orang kulit putih di US, $60 \%$ sampai $65 \%$ anak-anak di kelompokkan dalam maloklusi kelas I. ${ }^{14}$ Maloklusi Angle kelas II lebih sering terlihat, terjadi pada individu dengan bibir atas yang menonjol dan dagu yang perkembangannya kurang baik. Maloklusi kelas III jarang terlihat, terjadi pada individu dengan tampilan dagu bawah yang menonjol dimana lengkung rahang dan bibir atas perkembangannya kurang baik. $^{10,15}$

Berdasarkan hasil penelitian ini, didapatkan maloklusi terbanyak responden dengan klasifikasi Angle kelas I modifikasi Dewey tipe 2 sebanyak 7 orang 23,3\%. Hasil penelitian ini serupa dengan hasil penelitian Tulika Tripathi et al di kota New Delhi India tahun 2007 yang hasilnya didapatkan maloklusi Angle kelas I tipe 2 paling banyak yaitu $30,9 \%$. Maloklusi tipe ini dapat terjadi disebabkan oleh kebiasaan buruk pada rongga mulut, antara lain berupa mengisap jempol dan mengisap jari, atau kebiasaan menjulurkan lidah. Dalam jangka waktu lama, kebiasaan ini akan menghasilkan kekuatan yang dapat menyebabkan kedua lengkung rahang atas dan bawah menjadi openbite dan akan membuat gigi insisif rahang atas posisinya lebih ke anterior. ${ }^{10,15,16}$

Hasil penelitian ini berbeda dengan hasil penelitian Ruchi Sharma et al di kota Jaipur, India tahun 2015 yang hasilnya menunjukkan Angle kelas I tipe 1 yang paling banyak yaitu 26,57\% dibandingkan dengan tipe lainnya. Perbedaan hasil penelitian ini dapat disebabkan pada penelitian yang dilakukan oleh Ruchi Sharma dkk, responden yang diteliti memiliki riwayat hilangnya gigi dari lengkung gigi sebelum gigi pengantinya mendekati erupsi. Bila hal ini tidak segera ditangani, akan menyebabkan kehilangan ruang dan menganggu keseimbangan oklusi dewasa. Bhalajhi menjelaskan gigi berjejal terjadi akibat tidak harmonisnya ukuran gigi dan panjang lengkung rahang misalnya ukuran gigi yang terlalu besar, lengkung rahang yang terlalu pendek atau jumlah gigi lebih dari normal. ${ }^{17-19}$

Pada penelitian ini didapatkan hasil maloklusi Angle kelas I tipe 5 paling sedikit yaitu sebanyak 1 orang 3,3\%. Maloklusi Angle kelas I tipe 5 merupakan maloklusi yang melibatkan hilangnya ruang pada bagian posterior sehingga terjadi molar permanen ke arah mesial. Hasil penelitian ini berbeda dengan hasil penelitian Mohan G dan Tulika Tripathi, hasilnya menunjukkan tidak ditemukan maloklusi Angle kelas I tipe 5 atau molar permanen ke arah mesial. Hal ini dapat disebabkan pada penelitian yang dilakukan Mohan G dan Tulika Tripathi, jarang dari responden yang mengalami kehilangan gigi sulung pada masa pertumbuhan dan perkembangan. Gigi sulung mempunyai peran yang sangat penting. Selain untuk merangsang pertumbuhan bakal gigi permanen, gigi sulung juga diperlukan untuk mempertahankan lengkung rahang dan memberikan tempat bagi erupsi gigi permanen. ${ }^{19-22}$

Pada umumnya, terdapat tiga penyebab terjadinya molar permanen ke arah mesial yaitu karies, ekstraksi dan faktor genetic (erupsi yang ektopik). Kehilangan pada lengkung rahang karena karies interproksimal adalah akibat pencabutan secara dini gigi molar sulung, dimana pada kebanyakan kasus terjadi iatrogenik. Erupsi gigi molar pertama permanen secara ektopik akan membentuk pola erupsi ke mesial yang bias ditemukan pada gigi rahang atas. Kehilangan ruangan pada gigi mola sulung juga dapat disebabkan kelalaian jangka panjang karena karies gigi. ${ }^{10,15,21}$ 
Responden dengan Angle kelas II divisi 1 dan divisi 2 jumlahnya sama banyak pada hasil penelitan ini yaitu masing-masing sebanyak 4 orang 13,3\%. Hasil penelitian ini berbeda dengan hasil penelitian Aslam A et al dan studi pada populasi Tmukur Karnakata-India yang menunjukkan hasil presentase kasus maloklusi Angle kelas II divisi 1 lebih banyak dari pada divisi 2. Gigi insisivus atas protusi dapat disebabkan oleh faktor genetik atau beberapa faktor lainnya seperti faktor lingkungan, jaringan lunak, misalnya bibir yang tidak kompeten dapat memengaruhi posisi insisivus atas karena hilangnya keseimbangan yang dihasilkan oleh bibir dan lidah sehingga insisivus atas protrusi, kebiasaan menghisap jari, dan adanya diskrepansi skeletal dalam jurusan sagital juga dapat menyebabkan jarak gigit yang besar. ${ }^{15,19,23-25}$

Responden dengan Angle kelas III tipe 1 lebih banyak dibadingkan tipe yang lainnya yaitu sebanyak 2 orang 6,7\%. Hasil penelitian Mohan $\mathrm{G}$ et al yang menunjukkan hasil presentase kasus gigi insisivus anterior edge to edge lebih banyak dari gigi geligi insisivus bawah berjejal namun tidak sama banyak dengan gigi geligi insisivus atas berjejal. Gigi insisivus anterior edge to edge dapat terjadi karena insisvus maksila miring ke lingual dan insisivus mandibula miring ke labial, pertumbuhan mandibula yang berlebihan, dan tinggi intermaksilaris anterior besar, maka fungsi bibir sering kurang sempurna. Gigi geligi insisivus atas berjejal dapat terjadi karena ketidakseimbangan antara ukuran lengkung gigi dengan lengkung rahang. Ketidakseimbangan ini terjadi karena besarnya ruang yang dibutuhkan untuk penyusunan gigi-geligi lebih besar dibandingkan lengkung yang tersedia. $^{14,20,26,27}$

\section{SIMPULAN}

Maloklusi klasifikasi Angle modifikasi Dewey dengan presentase terbanyak adalah kelas I tipe dua 23,3\% responden, diikuti responden dengan jenis maloklusi kelas I tipe satu $20 \%$ responden. Jenis maloklusi kelas II divisi 1 dan divisi 2 sama banyak yaitu sebanyak 13,3 \% responden. Jenis maloklusi kelas III tipe 1 yaitu 6,7\% responden.

\section{SARAN}

1. Perlu dilakukan penyuluhan kepada masyarakat secara berkala oleh klinisi untuk mengoptimalkan pelayanan pencegahan maloklusi.

2. Dapat dilakukan penelitian lebih lanjut mengenai maloklusi berdasarkan faktor-faktor yang mempengaruhi terjadinya maloklusi.

\section{DAFTAR PUSTAKA}

1. Albarakati SF. Self-Perception Of Malocclusion Of Saudi Patients Using The Aesthetic Component Of The IOTN Index. Pakistan Oral \& Dental Journal. 2007;27(1):45-51.

2. Brito DI, Dias PF, Gleiser R. Prevalence of Malocclusion in Children Aged 9 to 12 Years Old in The City of Nova Friburgo, Rio de Janeiro State, Brazil. Rev Dent Press Ortod Ortop Facial. 2009;14:118-24.

3. Kharat S, Kharat SS, Thakkar P, Shetty RS, Pooja VK, Kaur K. Oral Habits and Its Relationship To Malocclusion: A Review. J Adv Med Dent Scie Res 2014:2(4):123-6.

4. Laguhi VA, Anindita PS, Gunawan PN. Gambaran Maoklusi Dengan Menggunakan HMAR Pada Pasien Di Rumah Sakit Gigi dan Mulut Universitas Sam Ratulangi Manado. eG. 2014;2(2).

5. Liu Z, McGrath C, Hagg U. The Impact of Malocclusion/Orthodontic Treatment Need On The Quality Of Life: A Systematic Review. Ang Orth.2009; 79(3):585-91.

6. Bittencourt MAV, Machado AW. An Overview Of The Prevalence Of Malocclusion In 6 to 10-Year-Old Children In Brazil. Dental Press J Orthod. 2010;15(6):113-22.

7. Susanto C. Need dan Demand serta akibat dari Maloklusi pada Siswa SMU Negeri 1 Binjai, Medan [Skripsi]. Medan: Universitas Sumatera Utara; 2010: p. 6-21. 
8. Lagana G, Masucci C, Fabi F, Bollero P, Cozza P. Prevalence of Malocclusions, Oral Habits And Orthodontiv Treatment Need In A 7to 15-Year-Old Schoolchildren Population In Tirana. Progress in Orthodontics. 2013;14:12.

9. Aftitah VB. Hubungan Maloklusi Terhadap Kualitas Hidup Remaja Dan Dewasa Muda Di RSGM Fakultas Kedokteran Gigi Universitas Hasanuddin Makassar. Skripsi. Universitas Hasanuddin; 2015. Hal 7-34

10.Sulandjari JCPH. Buku Ajar Ortodonsia I KGO I. Yogyakarta: Universitas Gadjah Mada, 2008; p. 1-43.

11.Sharma JN. Pattern of Distribution of Malocclusions in Patients Seeking Orthodontic Treatment at BPKIHS from Sunsari District of Nepal. Health Renaissance. 2010;8(2):93-6.

12.Theran M, Chugh VK, Sharma S. Prevalence Of Malocclusion In Jaipur, India. International Journal of Clinical Pediatric Dentistry. 2009; 2(1):23-5.

13.Wijayanti P, Krisnawati, Ismah $\mathbf{N}$. Gambaran Maloklusi dan Kebutuhan Perawatan Ortodonti Pada Anak Usia 9-11 Tahun (Studi Pendahuluan di SD At-Taufiq, Cempaka Putih, Jakarta). Jurnal PDGI. 2014;63(1):25-9.

14. Singh G. Textbook of Orthodontics (2nd ed). New Delhi: Jaypee Brothers Medical Publisher (P) Ltd, 2007; p. 1704.

15.Sulandjari JCPH. Buku Ajar Ortodonsia III KGO III. Yogyakarta: Universitas Gadjah Mada, 2008; p. 1-45.

16.Alam MK. A To Z Orthodontics Volume 03: Malocclusion. ISBN: 978-6975547-92-8; 1-35.

17.Iswari H. Gigi Supernumerary dan Perawatan Ortodonsi. Jurnal WIDYA Kesehatan dan Lingkungan. 2013;1(1):37-45.

18. Sharma R, Sharma K, Yadav Dhruv, Choudhary A, Singh Swapni. A Study Determine the Prevalence Of Malocclusion and Chief Motivational
Factor For Desire of Orthodontic Treatment in Jaipur City, India. World Journal of Dentistry, AprilJune 2015;6(2): page87-92.

19.Dewi O. Analisis Hubungan Maloklusi Dengan Kualitas Hidup Pada Remaja SMU Kota Medan Tahun 2007 [Tesis]. Medan: Universitas Sumatera Utara; 2008: 107.

20.Govindarajan M, Reddy VN, Ramalingam K, Durai KS, Rao PA, Prabhu A. Prevalence of Traumatic Dental Injuries to The Anterior Teeth Among to Thirteen Year Old School Children of Tamilnadu. Journal Contemporary Clinical Dentistry. 2015;3(2);164-7.

21.CERIL FKG UGM and Exhibition. Majalah Kedokteran Gigi. Yogyakarta: Universitas Gajah Mada. Yogyakarta, 2013 hal 1-58. Available from: ceril.fkg.ugm.ac.id >cerilDES2013

22.Rahhal AA. Extraction Timing Of Heavily Destructed Upper First Permanent Molars. Journal of Stomatology. 2014;1(4):161-8.

23.Sulandjari JCPH. Buku Ajar Ortodonsia III KGO III. Universitas Gadjah Mada, Yogyakarta, 2008; p. 1-45.

24.Aslam A, Naeem A, Jan H, Bukhari GA, Abbas Q, Amjad M. Prevalence Of Class II Malocclusions Pakistani Sample-A Study. Journal Oral and Dental Pakistan. 2010;30(1):96-100.

25.Sridharan $K$, Udapa $V$, Srinivas $H$, Kumar S, Sandbhor S. Prevalence of Class II Malocclusion in Turkum Population. Journal of Dental Sciences and Research. 2011;2(2):147.

26.Arsie RY. Dampak Berbagai Karakteristik Oklusi Gigi Anterior Terhadap Status Psikososial Remaja Awal [Tesis]. Jakarta: Universitas Indonesia; 2012: 1-75.

27.Brunharo I. Surgical Treatment of Dental and Skeletal Class III Malocclusion. Dental Press Journal of Orthodontics. 2013;18(1):143-9. 